\title{
Atrophy and programmed cell death of skeletal muscle
}

\author{
LM Schwartz ${ }^{*}, 1,2$
}

Striated skeletal is subject to nonlethal cycles of atrophy in response to a variety of physiological and pathological stimuli, including: starvation, disuse, denervation and inflammation. These cells can also undergo cell death in response to appropriate developmental signals or specific pathological insults. Most of the insights gained into the control of vertebrate skeletal muscle atrophy and death have resulted from experimental interventions rather than natural processes. In contrast, the intersegmental muscles (ISMs) of moths are giant cells that initiate sequential and distinct programs of atrophy and death at the end of metamorphosis as a normal component of development. This model has provided fundamental information about the control, biochemistry, molecular biology and anatomy of naturally occurring atrophy and death in vivo. The ISMs have provided a good complement to studies in vertebrates and may provide insights into clinically relevant disorders.

Cell Death and Differentiation (2008) 15, 1163-1169; doi:10.1038/cdd.2008.68; published online 16 May 2008

\section{Vertebrate Skeletal Muscle Development and Death}

Striated skeletal muscle is the largest tissue in the body and accounts for about $40 \%$ of its total mass and $75 \%$ of its cellular mass. It also represents the body's primary amino acid reservoir, and as such, is subject to protracted periods of nonpathological atrophy and hypertrophy in response to starvation, activity and development. Skeletal muscle also undergoes cell death as a normal component of development or in response to pathological stimuli.

Skeletal muscles arise during embryogenesis from a pool of lineage restricted precursor stem cells known as myoblasts. Classical embryological studies have demonstrated that myoblasts typically arise in the somites in response to a variety of inductive and repressive signals emanating from the neural tube and floor plate/notochord, as well as the lateral ectoderm and mesoderm. ${ }^{1,2}$ Newer data suggest that myoblasts may also be derived from other tissues. ${ }^{3}$ Myoblasts migrate to the back or limb buds where they proliferate and assume one of three distinct fates. One subset upregulates a variety of muscle-specific basic helix-loop-helix transcription factors, including MyoD, myocyte enhancer factor-2 and myogenin, and then undergoes terminal differentiation to form multinucleated muscle fibers (Figure 1). ${ }^{1,4}$ In vitro studies suggest that these cells also express several survival proteins, including AKT, phosphoinositide-3 kinase and the cyclin-dependent protein kinase inhibitor p21.5,6 Expression of these proteins presumably contributes to the extreme apoptosis resistance displayed by myotubes and muscle fibers.
A second subset of myoblasts, termed satellite cells because of their location between the basal lamina and sarcolemma, exit from cell cycle but fail to undergo myogenesis (Figure 1). ${ }^{1}$ These cells require the expression of the transcription factor Myf-5 and Pax-7 for differentiation ${ }^{1,7}$ and appear to express the antiapoptotic protein $\mathrm{Bcl}-2$ as their primary survival factor. ${ }^{8}$ Satellite cells are lineage restricted stem cells that can be induced to proliferate in response to focal injury, such as follows extreme exercise. ${ }^{9}$ The progeny of satellite cells can repair damaged muscle, form new muscle fibers or replace themselves. In some diseases, such as Duchenne Muscular Dystrophy, the satellite pool becomes exhausted and the muscles lose the capacity for repair. ${ }^{10,11}$

Like surplus precursor cells in other lineages, myoblasts that fail to differentiate or express appropriate survival proteins typically undergo programmed cell death by apoptosis (Figure 1). ${ }^{12,13}$ This 'default' to apoptosis may be triggered through TNF receptor TRAIL. ${ }^{14}$

Skeletal muscles are very plastic cells in terms of their mass and undergo atrophy in response to a variety of noxious stimuli, including: sarcopenia, denervation, disuse, sepsis, cancer, cachexia, or glucocorticoid treatment. ${ }^{15}$ While a variety of different signal transduction pathways control the activation of this process, the gross loss of muscle mass is ultimately mediated by two general mechanisms. The first is the ubiquitin-proteasome system (UPS). ${ }^{16}$ Inhibitors of the UPS greatly attenuate muscle protein loss following a variety of insults. ${ }^{17}$ Recently, this role was elegantly demonstrated in genetic studies that targeted the RING finger ubiquitin E3 ligases MuRF1 and Atrogin. ${ }^{18,19}$ Loss-of-function mutations in either of these genes is sufficient to reduce muscle atrophy in

\footnotetext{
${ }^{1}$ Department of Biology, University of Massachusetts, Amherst, MA, USA and ${ }^{2}$ Pioneer Valley Life Sciences Institute, Springfield, MA, USA

${ }^{*}$ Corresponding author: LM Schwartz, Department of Biology, Morrill Science Center, University of Massachusetts, Amherst, MA 01003, USA. Tel: + 413 545 2435;

Fax: + 413545 3243; E-mail: LMS@bio.umass.edu

Keywords: apoptosis; autophagy; Manduca sexta; intersegmental muscle; myogenesis

Abbreviations: ISMs, intersegmental muscles; UPS, ubiquitin-proteasome system; 20E, 20-hydroxyecdysone; APO III; apolipoprotein III

Received 08.2.08; revised 08.4.08; accepted 08.4.08; Edited by G Melino; published online 16.5.08
} 


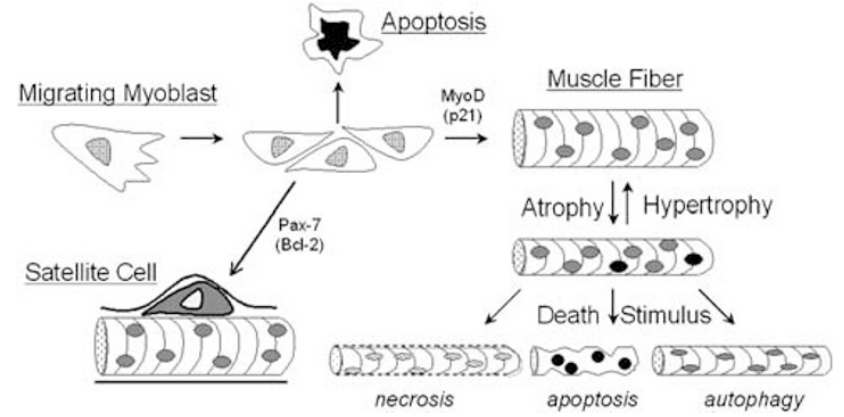

Figure 1 Muscle development and death in vertebrates. Myoblasts are muscle stem cells that migrate to their targets in the trunk and limb buds. At some point during maturation, the cells are forced to choose one of three distinct fates. Some cells become lineage-restricted stem cells known as satellite cells because of their location between the basement membrane and the sarcolemma. These cells express several transcription factors including Pax-7 and Myf-5, as well as the antiapoptotic Bcl-2 protein. A second population of cells fuses to form multinucleated muscle fibers. These cells express the transcription factors MyoD and myogenin and several survival proteins, including p21. A final group of cells fail to either differentiate or activate survival proteins, and then undergo programmed cell death via apoptosis. Muscle fibers can be induced to undergo atrophy in response to a wide variety of stimuli, including glucocorticoids, denervation or starvation. This process is nonlethal and muscle mass can be restored under some circumstances. There is still controversy regarding the apoptotic death of myonuclei within atrophic muscle fibers (denoted by the black nuclei). Muscle fibers can also be induced to die via necrosis, autophagy and apoptosis, depending on the stimulus and developmental programming of the cell

response to a variety of noxious stimuli. A third ubiquitin E3 ligase, NEDD-4, has been shown to facilitate muscle atrophy in response to denervation and unloading, but not from cachexia. $^{20}$

The second major mechanism responsible for muscle protein loss during atrophy is the autophagy/lysosome pathway. ${ }^{21}$ Autophagy is an ancient survival program that allows cells to literally consume themselves during times of extreme nutrient deprivation. ${ }^{22}$ During autophagy, double-membrane vesicles known as autophagosomes form around bulk cytoplasm and whole organelles such as mitochondria, and then fuse with lysosomes where the contents of the vesicles are degraded. While the autophagic- and UPS-dependent muscle atrophy programs are distinct, they can be coordinately regulated in cells via the FoxO3 transcription factor. ${ }^{23}$

It has been reported that when skeletal muscle undergoes atrophy that a subset of myonuclei undergo apoptosis, even though the rest of the muscle fibers themselves remain intact. ${ }^{24}$ These data have been used to support the hypothesis that muscle fibers carefully maintain their nuclear-to-cytoplasmic ratio even during atrophy. ${ }^{25}$ One potential interpretation of these results is that the loss of myonuclei may functionally reduce the abundance of mRNAs encoding muscle proteins, which in turn helps shift the cells from anabolism to the catabolism that accompanies atrophy. ${ }^{16}$ This model has been challenged recently in an elegant series of experiments that monitored nuclei in the same muscle fibers, in vivo, over the course of up to 1 month following atrophic insults. ${ }^{26}$ These authors demonstrated that atrophy occurs in the absence of demonstrable myonuclear loss. While they did confirm that atrophy is accompanied by a substantial increase in apoptosis within the muscle tissue, they provided compelling data that the apoptotic nuclei were derived from mononucleated stromal or satellite cells, but not myonuclei from within the muscle fibers itself.

Although differentiated striated skeletal muscle is very apoptosis resistant, these cells can be induced to undergo apoptosis in response to either toxins such as staurosporin ${ }^{27}$ or as part of a developmental program, such as the regression of the tadpole tail during amphibian metamorphosis (Figure 1). ${ }^{28}$ However, necrosis is the normal mechanism of cell death in skeletal muscle that has been exposed to a highly toxic stimulus (Figure 1).

\section{Intersegmental Muscles as a Model for Developmentally Regulated Atrophy and Death}

Most of the studies reported above relied on experimental manipulation to induce muscle atrophy or death followed pathological stimuli, such as denervation, immobilization or exposure to toxins. These data provide insight into the kinds of processes that may occur during pathogenesis, but may not fully reflect the endogenous mechanisms that are activated during normal development and homeostasis. One animal model that does not rely on experimental intervention to induce either atrophy or death is the intersegmenal muscle (ISMs) of moths. These giant muscle cells undergo a normal hormonally controlled atrophy that results in a $40 \%$ loss of muscle mass during the 3 days preceding adult emergence (eclosion). ${ }^{29}$ More striking is the fact that the cells then die and disappear during a 30-hour period coincident with adult eclosion at the end of metamorphosis (described in detail below). ${ }^{30,31}$ In fact, the term 'programmed cell death' (PCD) was coined in by Richard Lockshin to describe the death of these cells. ${ }^{30}$

The ISMs arise in the embryo and attach to each of nine of the segmental boundaries within the abdomen to create eight adjacent sheets of muscle. Each individual fiber within the ISMs is about $5 \mathrm{~mm}$ long and up to $1 \mathrm{~mm}$ in diameter (Figure $2 a, c$ and d). Coordinated contraction of the ISMs allows the caterpillar to crawl, the pupa to defend itself, and the adult moth to extricate itself from the overlying pupal cuticle at the end of metamorphosis. The ISMs are not required for any adult-specific behaviors and subsequently undergo PCD (Figure 2a and b).

Shortly after pupation, the ISMs in the first two and last two abdominal segments initiate PCD and disappear during the next 30-plus hours. The remaining four segments of ISMs, which appear to be anatomically identical to the early dying cells, persist throughout the rest of pupal-adult development. It is unclear why some ISMs die at the beginning of metamorphosis and the remainder at the end, but differential expression of embryonic gap, pair-rule, and/or segmentpolarity genes during embryogenesis may provide these groups with unique segmental identities.

\section{The Physiology of Atrophy}

Three days before adult eclosion the ISMs initiate a program of atrophy that results in a $40 \%$ loss of muscle mass and a $15-20 \%$ decline in fiber volume by the time of eclosion. ${ }^{29,30,32}$ 


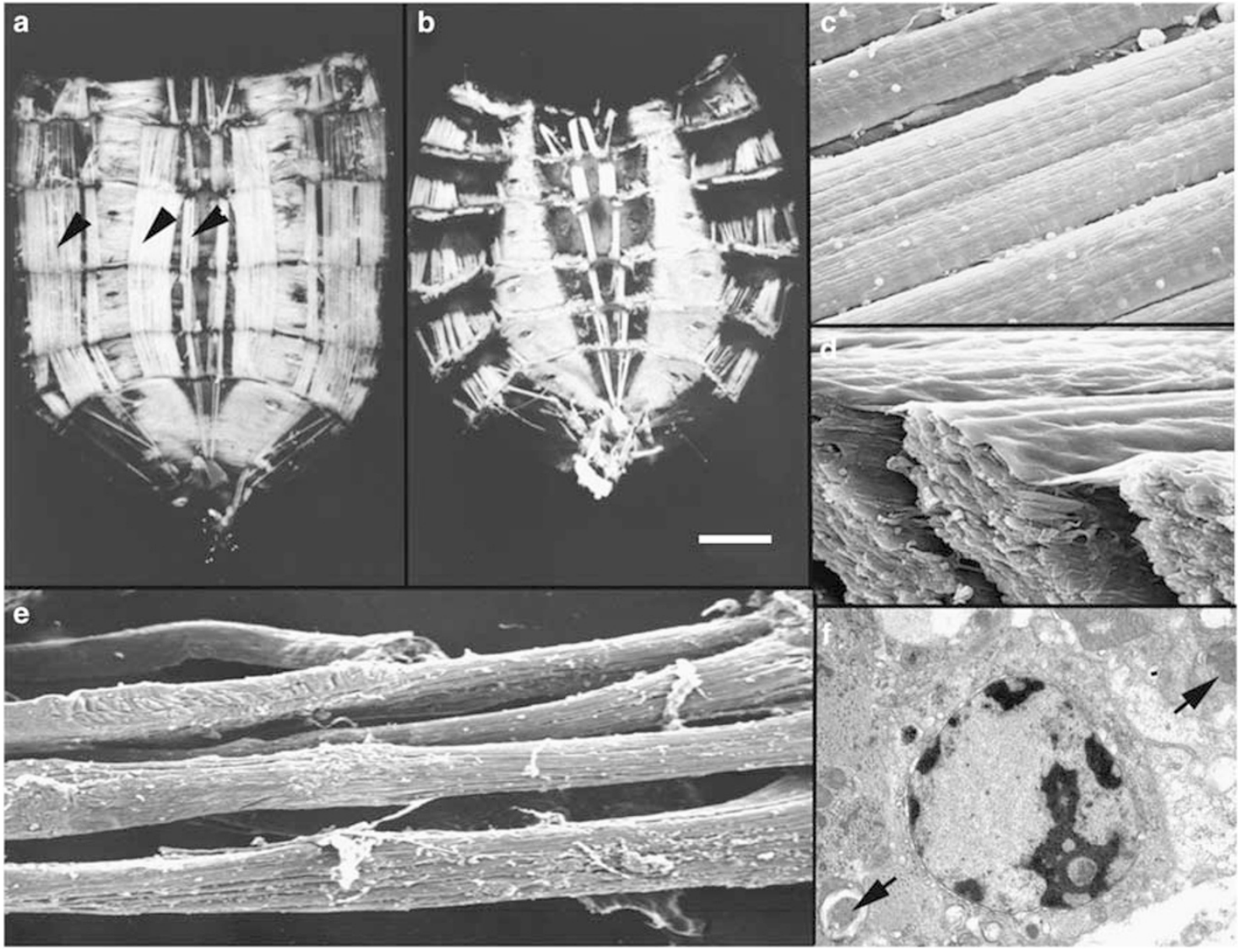

Figure 2 Morphology of ISM death in Manduca. The morphology of the ISMs at the light (a, b), scanning electron microscopic (c-e), and transmission electron microscopic (f) levels. The ISMs were examined in the abdomens of newly eclosed adults (a) and 30-hour old adults (b). Three sets of bilaterally symmetric ISMs span four abdominal segments (arrowheads) in the newly ecdysed adult but they disappear during the subsequent 30 hours. Other abdominal muscle groups are spared and persist throughout adulthood. The ISMs are composed of large, well-defined muscle fibers $(\mathbf{c}, \mathbf{d})$ that rapidly lose mass as they die $(\mathbf{e})$. This death is cell autonomous and the dying fibers are not phagocytosed (f). Ultrastructural analysis of the ISMs during death reveals pyknotic nuclei and numerous autophagic vesicles (arrows) (f). Scale approximately $=5 \mathrm{~mm}(\mathbf{a}, \mathbf{b})$, $10 \mu \mathrm{m}(\mathbf{c}), 4 \mu \mathrm{m}(\mathbf{d})$ and $40 \mu \mathrm{m}(\mathbf{e})$ and $2 \mu \mathrm{m}(\mathbf{f})$

Atrophy is not accompanied by changes in muscle physiological parameters such as: resting potential, force/ cross-sectional area, tentanic contracture, or sensitivity to intracellular calcium in skinned fiber preparations. ${ }^{33}$ There is also no overt change in the stochiometric levels of the major contractile proteins. ${ }^{34,35}$ These data support the hypothesis that atrophy involves a general increase in protein catabolism rather than the selective loss-specific contractile proteins as has been been shown in mammals. ${ }^{36}$ Supporting this hypothesis is the observed increase polyubiquitin mRNA expression and ubiquitin-dependent proteolysis during the period of atrophy (Figure 3). ${ }^{40,41}$

\section{Triggers for ISM Cell Death}

All known examples of muscle PCD in insects are triggered by hormonal cues. ${ }^{42}$ In Manduca, there is a circadian decline in the titer of the insect molting hormone 20-hydroxyecdysone (20E) during the last several days of pupal-adult development that determines the timing of many of the terminal events in metamorphosis, including the onset of atrophy and the initiation of ISM PCD. ${ }^{29}$ Maintaining an elevated level of $20 \mathrm{E}$ is sufficient to delay ISM death indefinitely, while a precocious drop in the circulating $20 \mathrm{E}$ titer can greatly advance the time of death.

\section{The Physiology of Death}

ISM death is not just the natural conclusion of the on-going atrophy process, but instead represents a distinct developmental program that induces the destruction of the contractile apparatus. ${ }^{29,31,43}$ Coincident with eclosion, the resting potential declines at a rate of about $2.5 \mathrm{mV} / \mathrm{h}$ and the mass at a rate of $\sim 4 \% / \mathrm{h} .{ }^{33}$ While the muscles are no longer contractile $15 \mathrm{~h}$ later, they still maintain a modest resting potential ( $\sim-30 \mathrm{mV}$ ), suggesting that there has been no membrane rupture or necrosis. By $30 \mathrm{~h}$ post-eclosion, almost all the muscle mass is gone and the fibers are composed of whorls of internalized membranes and connective tissue. ${ }^{43,44}$

In mammals, dying cells are almost always phagocytosed by either neighboring cells or circulating macrophages. ${ }^{45}$ This is also the ultimate fate for most dying cells in insects, which tend to be consumed by circulating hemocytes. ${ }^{46}$ Interestingly, dying ISMs are not phagocytosed and do not even attract circulating macrophages, suggesting that they do not produce the normal membrane-associated signals that are 


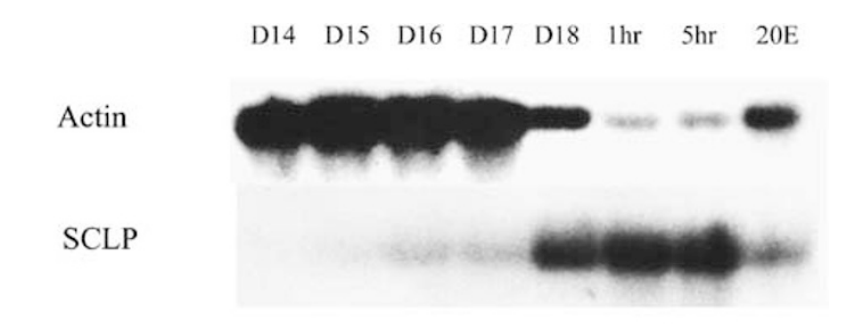

Polyubiquitin

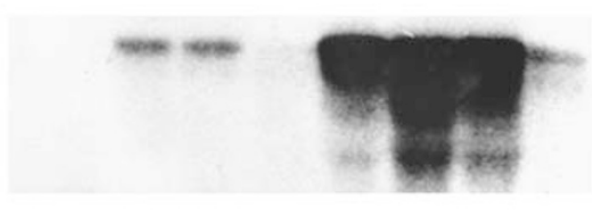

UBF-80

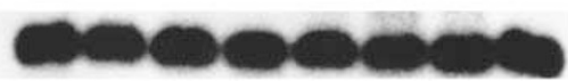

Figure 3 Differential gene expression in the intersegmental muscles. The ISMs begin to atrophy on day 15 of pupal adult development and then initiate programmed cell death coincident with adult eclosion late on day 18 . By $5 \mathrm{~h}$ posteclosion the muscles have lost significant mass and physiological function. ${ }^{33}$ Most genes are constitutively expressed, like the ubiquitin fusion 80 (Ubf-80) gene, which plays a role in ribosome biogenesis. ${ }^{37} \mathrm{~A}$ small number of genes are induced or repressed with the commitment to die. Actin mRNA goes from being one of the most abundant transcripts within the ISMs prior to eclosion to all but disappearing in the dying cells. ${ }^{38}$ Conversely, expression of the Small Cytoplasmic Leucine Rich Repeat Protein (SCLP) is almost undetectable in the muscles prior to day 18 and then is dramatically induced with the commitment to die. ${ }^{39}$ Polyubiquitin is transiently induced on day 15 , coincident with the onset of atrophy, and then is expressed at very high levels on day $18 .^{40}$ All of the death-associated changes in transcript abundance can be prevented with injection of $25 \mu \mathrm{g}$ of 20 -hydroxyecdysone $(20 \mathrm{E})$ on day $17 . \mathrm{D}=$ day of pupal-adult development, $\mathrm{hr}=$ hours post-eclosion; $20 \mathrm{E}=20$-hydroxyecdysone

expressed by most dying cells (Figure 2e). ${ }^{43,46}$ Instead, the ISMs not only commit suicide, they also assume responsibility for the subsequent removal of the corpse. Interestingly, hemocytes do associate with the sarcolemma of some other dying muscles in Manduca, where they may function in remodeling the muscle to facilitate the de novo formation of new muscle groups during metamorphosis. ${ }^{47}$

\section{The Morphology of Atrophy and Death}

The ISMs do not display any of the classic features of apoptosis, including: nuclear condensation, DNA ladders, membrane blebbing, caspase activation, or phagocytosis (Figure 2e). ${ }^{43,46,48,49}$ Instead, ISM death is accompanied by a dramatic increase in the number of both lysosomes and autophagic vesicles rich in cytoplasm and mitochondria (Figure 2f). ${ }^{43,50}$ In some systems, autophagy can serve to protect cells from nutrient deprivation or as a component of subsequent cell death. ${ }^{51}$ In the case of the ISMs, the autophagic process continues until the muscles become devoid of identifiable organelles or defined internal structure ${ }^{35} \mathrm{It}$ is unclear if autophagy just serves to recycle the bulk of the cytoplasm and contractile apparatus or also plays an active role in death. The drug chloroquine, which can inhibit autophagy, inhibited the disolution of the fibers but not muscle death, suggesting that autophagy may not be a triggering event. ${ }^{52}$ However, the answer to this question awaits the application of more specific tools, such as the use of RNAi directed against essential autophagic proteins. ${ }^{53}$

\section{Molecular Mechanisms Controlling Atrophy and Death}

The ability of the ISMs to die at the end of metamorphosis requires de novo gene expression, and this model provided the first examples of differential gene expression during PCD. ${ }^{54,55}$ Using both molecular and proteomic methods, several genes have been identified that are induced or repressed with the commitment of the ISMs to die (Figure 3, Table 1).

The first cell death-associated gene isolated from the ISMs encoded polyubiquitin. ${ }^{56}$ Manduca has two alleles of polyubiquitin, one that encodes 9 head-to-tail repeats of the ubiquitin monomer and a second that encodes $18 .{ }^{65}$ Translation and protein processing of these transcripts provides the cell with a mechanism to rapidly increase the free ubiquitin pool. The induction of polyubiquitin in condemned ISMs is tightly coupled to the cell death process since judicious injection of $20 \mathrm{E}$ can delay both cell death and the expression of this polyubiquitin mRNA. ${ }^{56}$ In fact, ISM death is associated with a coordinated increase in all components of the ubiquitin-proteasome pathway, including: ubiquitin, $20 \mathrm{~S}$ and $26 \mathrm{~S}$ proteasome subunits, and E2 ubiquitin protein conjugases. ${ }^{41,59,66,57}$ The induction of the ubiquitin-proteasome pathway presumably serves to facilitate protein loss during PCD, especially since the cells are not phagocytosed. ${ }^{46}$ Bayline et al. ${ }^{32}$ have shown that pharmacological inhibition of the proteasome is sufficient to block the initiation of ISM death. As an ubiquitin-proteasomedependent step is also required for many apoptotic cell deaths ${ }^{67}$ the loss of cell death inhibitor(s) may be a key step in all PCDs.

Because adult Manduca only feed on nectar, the amino acid reserves liberated from the dying cells presumably serve as a valuable resource for the adult. Muscles are also lipid reservoirs with extensive internal membrane systems including the $T$ tubule system and sarcoplasmic reticulum. One of the genes that is dramatically induced when the ISMs become committed to die is apolipoprotein III (ApolII), a lipid transport protein. ${ }^{64}$ Functional studies have not been performed with the ISMs, but it has been speculated that it helps recycle ISM lipids to the blood for utilization by other tissues. As with all the other cell death-associated transcripts in the ISMs, the expression of Apolll is regulated by the $20 \mathrm{E}$ titer at the end of development.

Some of the genes isolated in the ISM screen encode novel proteins that may function as signal transduction proteins. For example, the newly described Acheron (Achn) protein is dramatically induced with the commitment of the ISMs to die. ${ }^{62}$ In humans and mouse, Achn is expressed in neurons, myoepithelial cells, skeletal muscle and cardiac muscle (C Brown, H Glenn, J Mueller and LM Schwartz, unpublished). Ectopic expression of Achn drives both myotube formation and apoptosis in mammalian myoblasts in vitro and zebrafish embryos in vivo, while blockade of Achn expression blocks both myogenesis and death ( $Z$ Wang, H Glenn, C Brown, J-X Liu, RO Karlstrom, and LM Schwartz, unpublished). Misregulation of Achn also appears to contribute to 
Table 1 Differentially expressed genes from condemned manduca ISMs

\begin{tabular}{|c|c|c|c|}
\hline Process & Gene & Expression & Reference \\
\hline Proteolysis & $\begin{array}{l}\text { Polyubiquitin } \\
14 \text { kDa E2 ubiquitin conjugase } \\
\text { 18-56 (Sug1) 26S proteosome ATPase } \\
\text { 28.1 kDa subunit catalytic subunit of } 20 \mathrm{~S} \text { proteasome } \\
\text { S6 (TBP7, MS73) } 26 \mathrm{~S} \text { proteosome ATPase } \\
\text { S6' (TBP1) 26S proteosome ATPase } \\
\text { S7 (MSS1) 26S proteosome ATPase } \\
\text { S10b (SUG2) 26S proteosome ATPase }\end{array}$ & $\begin{array}{l}\text { Induced } \\
\text { Induced } \\
\text { Induced } \\
\text { Repressed } \\
\text { Induced } \\
\text { Induced } \\
\text { Induced } \\
\text { Induced }\end{array}$ & $\begin{array}{l}56 \\
41 \\
57 \\
58 \\
59 \\
58 \\
58 \\
58\end{array}$ \\
\hline Transcription & E75B & Repressed & 60 \\
\hline Translation & $\begin{array}{l}\text { elF1A translation-initiation factor } \\
\text { Oskar (maternal effect protein) }\end{array}$ & $\begin{array}{l}\text { Induced } \\
\text { Repressed }\end{array}$ & $\begin{array}{l}60 \\
61\end{array}$ \\
\hline Signal transduction & $\begin{array}{l}\text { Acheron (putative RNA-binding protein) } \\
\text { Small cytoplasmic repeat protein (SCLP) } \\
\text { G-coupled-receptor GPR85 } \\
\text { Calmodulin-dependent calcineurin A1 subunit } \\
\text { Death-associated LIM-only protein (DALP) (insect ortholog of Hic-5) }\end{array}$ & $\begin{array}{l}\text { Induced } \\
\text { Induced } \\
\text { Induced } \\
\text { Induced }\end{array}$ & $\begin{array}{l}62 \\
61 \\
61 \\
63\end{array}$ \\
\hline Metabolism & $\begin{array}{l}\text { Apolipoprotein III } \\
\text { Low molecular wt lipoprotein PBMHPC-23 } \\
\text { Hydroxy acid oxidase } 1\end{array}$ & $\begin{array}{l}\text { Induced } \\
\text { Induced } \\
\text { Induced }\end{array}$ & $\begin{array}{l}64 \\
61 \\
61\end{array}$ \\
\hline Contractile protein & $\begin{array}{l}\text { Actin } \\
\text { Myosin heavy chain } \\
\text { Myosin light chain } \\
\text { Myosin regulatory Light chain isoforms } 1 \text { and } 2 \\
\text { Calponin } 1 \\
\text { Troponin I }\end{array}$ & $\begin{array}{l}\text { Repressed } \\
\text { Repressed } \\
\text { Repressed } \\
\text { Repressed } \\
\text { Repressed } \\
\text { Repressed }\end{array}$ & $\begin{array}{l}38 \\
38 \\
61 \\
61 \\
61 \\
61\end{array}$ \\
\hline
\end{tabular}

pathogenesis in human mammary ductal carcinomas and myoblast-derived rhabdomyosarcomas ( $R$ Shao, H Glenn, S Scully, J Mueller, and LM Schwartz, unpublished). These data suggest that Achn acts at an early point in differentiation and death in muscle and perhaps other tissues.

ISM death is also associated with the repression of the genes encoding actin and myosin heavy chain (Figure 3, Table 1) ${ }^{38}$ Part of this control presumably reflects transcriptional regulation, since it is coordinated with the de novo expression of the cell death associated transcripts described above. The coordinated repression of structural genes and the induction of genes associated with cell death, allows the newly expressed transcripts to represent a greater percentage of the message pool and facilitate rapid muscle degradation.

In additional to transcriptional control, there may also be post-translational control of gene expression. ${ }^{68}$ Analysis of cell-free extracts of Manduca ISMs has demonstrated that all mRNAs analyzed displayed a significant reduction in half-life on the day preceding ISM death. This regulation was dependent on sequences present in the $3^{\prime}$ untranslated regions of the transcripts and could be transferred to ectopic mRNAs such as $\beta$-galactosidase. In the ISMs, actin mRNA stability and translatability may be regulated in part through the AU-rich elements (AREs) present in its $3^{\prime}$ untranslated region. ${ }^{68}$ AREs are key regulatory sites and recent studies have demonstrated that the binding of microRNAs to AREs can serve as a switch to both enhance and repress translatability of specific mRNAs. ${ }^{69-71}$ Thus, the regulation of gene expression in the ISMs may be regulated at multiple levels.

\section{Concluding Remarks}

Skeletal muscle atrophy and death are major contributors to human morbidity and mortality, and interventions that can block or retard these processes would be of obvious therapeutic value. The intersegmental muscles of moths have proven to be a powerful tool for examining the molecular mechanisms that mediate atrophy and death. In addition to providing the field with its name, the ISMs were the source for the first cloned cell death-associated transcripts and were one of the first models to demonstrate a role of the ubiquitin/ proteasome pathway in muscle atrophy and death. Data from the ISMs also support the hypothesis that activation of programmed cell death is coupled to mRNA stability and raises the possibility that this process may be modulated by microRNAs, a largely unexplored area of regulation. Lastly, the ISMs constitute a powerful system for studying the role of autophagy in atrophy and cell death.

Acknowledgements. I am very grateful to Priscilla Clarkson, Christine Brown, and Zheng-Liang Gao for critically reading the article and to Kristian Gundersen for sharing unpublished data. Work presented in this review was supported by grants from the National Institutes of Health, Center of Excellence in Apoptosis Research, Department of Defense, Collaborative Biomedical Research Program and Rays of Hope Foundation.

1. Buckingham M, Bajard L, Chang T, Daubas $P$, Hadchouel J, Meilhac $S$ et al. The formation of skeletal muscle: from somite to limb. J Anat 2003; 202: 59-68.

2. Grefte S, Kuijpers-Jagtman AM, Torensma R, Von den Hoff JW. Skeletal muscle development and regeneration. Stem Cells Dev 2007; 16: 857-868.

3. Biressi S, Molinaro M, Cossu G. Cellular heterogeneity during vertebrate skeletal muscle development. Dev Biol 2007; 308: 281-293. 
4. Berkes CA, Tapscott SJ. MyoD and the transcriptional control of myogenesis. Semin Cell Dev Biol 2005; 16: 585-595.

5. Fujio Y, Guo K, Mano T, Mitsuuchi Y, Testa JR, Walsh K. Cell cycle withdrawal promotes myogenic induction of Akt, a positive modulator of myocyte survival. Mol Cell Biol 1999; 19 : 5073-5082.

6. Ostrovsky O, Bengal E. The mitogen-activated protein kinase cascade promotes myoblast cell survival by stabilizing the cyclin-dependent kinase inhibitor, p21WAF1 protein. J Biol Chem 2003; 278: 21221-21231.

7. Buckingham M, Relaix $F$. The role of Pax genes in the development of tissues and organs: Pax3 and Pax7 regulate muscle progenitor cell functions. Annu Rev Cell Dev Biol 2007; 23 645-673.

8. Dominov JA, Houlihan-Kawamoto CA, Swap CJ, Miller JB. Pro- and anti-apoptotic members of the Bcl-2 family in skeletal muscle: a distinct role for Bcl-2 in later stages of myogenesis. Dev Dyn 2001; 220: 18-26.

9. Le Grand F, Rudnicki MA. Skeletal muscle satellite cells and adult myogenesis. Curr Opin Cell Biol 2007; 19: 628-633.

10. Shi X, Garry DJ. Muscle stem cells in development, regeneration, and disease. Genes Dev 2006; 20: 1692-1708.

11. Péault B, Rudnicki M, Torrente Y, Cossu G, Tremblay JP, Partridge T et al. Stem and progenitor cells in skeletal muscle development, maintenance, and therapy. Mol Ther 2007; 15: 867-877

12. Dee K, Freer M, Mei $\mathrm{Y}$, Weyman $\mathrm{CM}$. Apoptosis coincident with the differentiation of skeletal myoblasts is delayed by caspase 3 inhibition and abrogated by MEK-independent constitutive Ras signaling. Cell Death Differ 2002; 9: 209-218.

13. Valavanis $C$, Hu Y, Yang Y, Osborne BA, Chouaib S, Greene L et al. Model cell lines for the study of apoptosis in vitro. Methods Cell Biol 2001; 66: 417-436.

14. O'Flaherty J, Mei Y, Freer M, Weyman CM. Signaling through the TRAIL receptor DR5/ FADD pathway plays a role in the apoptosis associated with skeletal myoblast differentiation. Apoptosis 2006; 11: 2103-2113.

15. Lynch GS, Schertzer JD, Ryall JG. Therapeutic approaches for muscle wasting disorders. Pharmacol Ther 2007; 113: 461-487.

16. Kandarian SC, Jackman RW. Intracellular signaling during skeletal muscle atrophy. Muscle Nerve 2006; 33: 155-165.

17. Tawa Jr NE, Odessey R, Goldberg AL. Inhibitors of the proteasome reduce the accelerated proteolysis in atrophying rat skeletal muscles. J Clin Invest 1997; 100: 197-203.

18. Gomes MD, Lecker SH, Jagoe RT, Navon A, Goldberg AL. Atrogin-1, a muscle-specific F-box protein highly expressed during muscle atrophy. Proc Natl Acad Sci USA 2001; 98: 14440-14445.

19. Bodine SC, Latres $E$, Baumhueter S, Lai VK, Nunez L, Clarke BA et al. Identification of ubiquitin ligases required for skeletal muscle atrophy. Science 2001; 294: $1704-1708$

20. Koncarevic A, Jackman RW, Kandarian SC. The ubiquitin-protein ligase Nedd4 targets Notch1 in skeletal muscle and distinguishes the subset of atrophies caused by reduced muscle tension. FASEB J 2007; 21: 427-437.

21. Bechet $D$, Tassa A, Taillandier D, Combaret $L$, Attaix D. Lysosomal proteolysis in skeletal muscle. Int J Biochem Cell Biol 2005; 37: 2098-2114.

22. Lum JJ, DeBerardinis RJ, Thompson CB. Autophagy in metazoans: cell survival in the land of plenty. Nat Rev Mol Cell Biol 2005; 6: 439-448.

23. Mammucari C, Milan G, Romanello V, Masiero E, Rudolf R, Del Piccolo $P$ et al. FoxO3 controls autophagy in skeletal muscle in vivo. Cell Metab 2007; 6: 458-471.

24. Liu CC, Ahearn JM. Apoptosis of skeletal muscle cells and the pathogenesis of myositis: a perspective. Curr Rheumatol Rep 2001; 3: 325-333.

25. Tews DS. Muscle-fiber apoptosis in neuromuscular diseases. Muscle Nerve 2005; 32 443-458.

26. Bruusgaard JC, Gundersen K. In vivo time-lapse microscopy reveals no loss of murine myonuclei during weeks of muscle atrophy. J Clin Invest 2008; 118: 1450-1457.

27. McArdle A, Maglara A, Appleton P, Watson AJ, Grierson I, Jackson MJ. Apoptosis in multinucleated skeletal muscle myotubes. Lab Invest 1999; 79: 1069-1076.

28. Kerr JF, Harmon B, Searle J. An electron-microscope study of cell deletion in the anuran tadpole tail during spontaneous metamorphosis with special reference to apoptosis of striated muscle fibers. J Cell Sci 1974; 14: 571-585.

29. Schwartz LM, Truman JW. Hormonal control of rates of metamorphic development in the tobacco hornworm Manduca sexta. Dev Biol 1983; 99: 103-114.

30. Lockshin RA, Williams CM. Programmed cell death - I. Cytology of degeneration in the intersegmental muscles of the pernyi silkmoth. J Insect Physiol 1965; 11: 123-133.

31. Schwartz LM, Truman JW. Peptide and steroid regulation of muscle degeneration in an insect. Science 1982; 215: 1420-1421.

32. Bayline RJ, Dean DM, Booker R. Inhibitors of ubiquitin-dependent proteolysis can delay programmed cell death of adult intersegmental muscles in the moth Manduca sexta. Dev Dyn 2005; 233: 445-455.

33. Schwartz LM, Ruff RL. Changes in contractile properties of skeletal muscle during developmentally programmed atrophy and death. Am J Physiol Cell Physiol 2002; 282 C1270-C1277.

34. Schwartz LM, Kosz L, Kay BK. Gene activation is required for developmentally programmed cell death. Proc Natl Acad Sci USA 1990; 87: 6594-6598.

35. Wadewitz AG, Lockshin RA. Programmed cell death: dying cells synthesize a co-ordinated, unique set of proteins in two different episodes of cell death. FEBS Lett 1988; 241: 19-23.
36. Ashley $\mathrm{Z}$, Sutherland $\mathrm{H}$, Lanmüller $\mathrm{H}$, Russold MF, Unger $\mathrm{E}$, Bijak $\mathrm{M}$ et al. Atrophy, but not necrosis, in rabbit skeletal muscle denervated for periods up to one year. Am J Physiol Cell Physiol 2007; 292: C440-C451.

37. Bishoff ST, Schwartz LM. Characterization of a ubiquitin-fusion gene from the tobacco hawkmoth, Manduca sexta. Nucleic Acids Res 1990; 18: 6039-6043.

38. Schwartz LM, Jones ME, Kosz L, Kuah K. Selective repression of actin and myosin heavy chain expression during the programmed death of insect skeletal muscle. Dev Biol 1993; 158: 448-455.

39. Kuelzer F, Kuah P, Bishoff ST, Cheng L, Nambu JR, Schwartz LM. Cloning and analysis of small cytoplasmic leucine-rich repeat protein (SCLP), a novel, phylogenetically-conserved protein that is dramatically up-regulated during the programmed death of moth skeletal muscle. J Neurobiol 1999; 4: 482-494.

40. Schwartz LM, Myer A, Kosz L, Engelstein M, Maier C. Activation of polyubiquitin gene expression during developmentally programmed cell death. Neuron 1990; 5: 411-419.

41. Haas AL, Baboshina O, Williams B, Schwartz LM. Coordinated induction of the ubiquitin conjugation pathway accompanies the developmentally programmed death of insect skeletal muscle. J Biol Chem 1995; 270: 9407-9412.

42. Fahrbach SE, Nambu JR, Schwartz LM. Programmed cell death in insect neuromuscular systems during metamorphosis. In: Gilbert LI, latrou K, Gill SS, (eds) Comprehensive Molecular Insect Science. Oxford: Elsevier Pergamon, 2005, pp 165-198.

43. Beaulaton J, Lockshin RA. Ultrastructural study of the normal degeneration of the intersegmental muscles of Anthereae polyphemus and Manduca sexta (Insecta, Lepidoptera) with particular reference of cellular autophagy. J Morphol 1977; 154: 39-57.

44. Lockshin RA, Beaulaton J. Programmed cell death electrophysiological and ultrastructural correlations in metamorphosing muscles of lepidopteran insects. Tissue Cell 1979; 11 803-819.

45. Erwig LP, Henson PM. Clearance of apoptotic cells by phagocytes. Cell Death and Diff 2008; 15: 243-250.

46. Jones ME, Schwartz LM. Not all muscles meet the same fate when they die. Cell Biol Int 2001; 25: 539-545.

47. Rheuben MB. Degenerative changes in the muscle fibers of Manduca sexta during metamorphosis. J Exp Biol 1992; 167: 91-117.

48. Schwartz LM, Smith SW, Jones ME, Osborne BA. Do all programmed cell deaths occur via apoptosis? Proc Natl Acad Sci USA 1993; 90: 980-984.

49. Zakeri ZF, Quaglino D, Latham T, Lockshin RA. Delayed internucleosomal DNA fragmentation in programmed cell death. FASEB J 1993; 7: 470-478.

50. Lockshin RA, Beaulaton J. Programmed cell death. Cytochemical appearance of lysosomes when death of the intersegmental muscles is prevented. J Ultrastruct Res 1974 46: 63-78.

51. Shimizu S, Kanaseki T, Mizushima N, Mizuta T, Arakawa-Kobayashi S, Thompson CB et al. Role of $\mathrm{Bcl}-2$ family proteins in a non-apoptotic programmed cell death dependent on autophagy genes. Nat Cell Biol 2004; 6: 1221-1228.

52. Lockshin RA, Beaulaton J. Programmed cell death. Chloroquine limits resorption but does not delay its onset- Ultrastructural and Biochemical Study. Biol Cellulaire 1979; 36: 37-42.

53. Hars ES, Qi H, Ryazanov AG, Jin S, Cai L, Hu C et al. Autophagy regulates ageing in $\mathrm{C}$. elegans. Autophagy 2007; 3: 93-95.

54. Lockshin RA. Programmed cell death. Activation of lysis by a mechanism involving the synthesis of protein. $J$ Insect Physiol 1969; 15: 1505-1516.

55. Schwartz LM, Kosz L, Kay BK. Gene activation is required for developmentally programmed cell death. Proc Natl Acad Sci USA 1990; 87: 6594-6598.

56. Schwartz LM, Myer A, Kosz L, Engelstein M, Maier C. Activation of polyubiquitin gene expression during developmentally programmed cell death. Neuron 1990; 5: 411-419.

57. Sun D, Sathyanarayana UG, Johnston SA, Schwartz LM. A member of the phylogenetically conserved CAD family of transcriptional regulators is dramatically upregulated during the programmed cell death of skeletal muscle in the tobacco hawkmoth Manduca sexta. Dev Biol 1996; 173: 499-509.

58. Löw P, Hastings RA, Dawson SP, Sass M, Billett MA, Mayer RJ et al. Localisation of $26 \mathrm{~S}$ proteasomes with different subunit composition in insect muscles undergoing programmed cell death. Cell Death Differ 2000; 7: 1210-1217.

59. Jones ME, Haire MF, Kloetzel PM, Mykles DL, Schwartz LM. Changes in the structure and function of the multicatalytic proteinase (proteasome) during programmed cell death in the intersegmental muscles of the hawkmoth, Manduca sexta. Dev Biol 1995; 169: 436-447.

60. Löw P, Talián GC, Sass M. Up- and downregulated genes in muscles that undergo developmentally programmed cell death in the insect Manduca sexta. FEBS Lett 2005; 579: 4943-4948.

61. Zhang $\mathrm{P}$, Aso $\mathrm{Y}$, Jikuya $\mathrm{H}$, Kusakabe T, Lee JM, Kawaguchi $\mathrm{Y}$ et al. Proteomic profiling of the silkworm skeletal muscle proteins during larval-pupal metamorphosis. J Proteome Res 2007; 6: 2295-2303

62. Valavanis C, Wang Z, Sun D, Vaine M, Schwartz LM. Acheron, a novel member of the Lupus Antigen family, is induced during the programmed cell death of skeletal muscles in the moth Manduca sexta. Gene 2007; 393: 101-109.

63. Hu Y, Cascone PJ, Cheng L, Sun D, Nambu JR, Schwartz LM. Lepidopteran DALP, and its mammalian ortholog HIC-5, function as negative regulators of muscle differentiation. Proc Natl Acad Sci USA 1999; 96: 10218-10223.

64. Sun D, Ziegler R, Milligan CE, Fahrbach S, Schwartz LM. Apolipophorin III is dramatically up-regulated during the programmed death of insect skeletal muscle and neurons. J Neurobiol 1995; 26: 119-129. 
65. Myer A, Schwartz LM. Allelic variation of the polyubiquitin gene in the tobacco hawkmoth Manduca sexta, and its regulation by heat shock and programmed cell death. Insect Biochem Mol Biol 1996; 26: 1037-1046.

66. Löw P, Bussell K, Dawson SP, Billett MA, Mayer RJ, Reynolds SE. Expression of a 26S proteasome ATPase subunit, MS73, in muscles that undergo developmentally programmed cell death, and its control by ecdysteroid hormones in the insect Manduca sexta. FEBS Lett 1997; 400: 345-349.

67. Yang Y, Fang S, Jensen JP, Weissman AM, Ashwell JD. Ubiquitin protein ligase activity of IAPs and their degradation in proteasomes in response to apoptotic stimuli. Science 2000; 288: 874-877.
68. Cascone PJ, Schwartz LM. Post-transcriptional regulation of gene expression during the programmed death of insect skeletal muscle. Dev Genes Evol 2001; 211: 397-405.

69. Jing $\mathrm{Q}$, Huang S, Guth S, Zarubin T, Motoyama A, Chen J et al. Involvement of microRNA in AU-rich element-mediated mRNA instability. Cell 2005; 120: 623-634.

70. Maitra S, Chou CF, Luber CA, Lee KY, Mann M, Chen CY. The AU-rich element mRNA decay-promoting activity of BRF1 is regulated by mitogen-activated protein kinaseactivated protein kinase 2. RNA 2008; 114: 950-959.

71. Vasudevan S, Tong Y, Steitz JA. Switching from repression to activation: microRNAs can upregulate translation. Science 2007; 318: 1931-1934. 